Oikos 116: 1547-1557, 2007

doi: $10.1111 /$ j.2007.0030-1299.15868.x,

Copyright (C) Oikos 2007, ISSN 0030-1299

Subject Editor: Esa Ranta, Accepted 24 April 2007

\title{
Do mountain hare populations cycle?
}

\author{
Scott Newey, Tomas Willebrand, Daniel T. Haydon, Fredrik Dahl, Nicholas J. Aebischer, \\ Adam A. Smith and Simon J. Thirgood
}

S. Newey (s.newey@macaulay.ac.uk), T. Willebrand and F. Dahl, Dept of Animal Ecology, Swedish Univ. of Agricultural Sciences, SE-90183 Umea, Sweden. - SN and Adam A. Smith, The Game Conservancy Trust, Dalwhinnie, Inverness-shire, UK, PH19 1AF. - SN and S. J. Thirgood, Macaulay Institute, Craigiebuckler, Aberdeen, UK, AB15 8QH. - TW also at: Dept of Forestry and Wildlife Management, Hedmark Univ. College, Evenstad, NO-2480 Koppang, Norway. - FD also at: Int. Inst. for Applied Systems Analysis, Schlossplatz 1, AU-2361 Laxenburg, Austria. - D. T. Haydon, Div. of Environmental and Evolutionary Biology, Univ. of Glasgow, Glasgow, UK, G12 8QQ. - N. J. Aebischer, The Game Conservancy Trust, Fordingbridge, Hampshire, UK, SP6 1EF.

\begin{abstract}
We investigated the occurrence and distribution of multi-annual cycles in abundance of mountain hare populations across a wide area of their range in northern Europe. We analysed 125 time-series of mountain hare abundance indexed from hunting bag records and questionnaire responses from Scotland, Sweden, Finland and Switzerland. We also reanalysed 17 previously published time-series based on hunting bag records and snow track indices from mountain hare populations in Scotland, Norway, Sweden, Finland, Russia and Italy. Autocorrelation analysis showed that $45 \%$ of mountain hare populations showed evidence of cycles, characterised by significant negative autocorrelations at half or the whole cycle period. The amplitude and periodicity of cycles varied between and within countries. Time-series in Scotland were characterised by highamplitude weak cycles with a mean periodicity of nine years but with a range of 4-15 years. Norwegian and Swedish time-series revealed low amplitude weak cycles with a 3-7 year period. Finnish time-series showed low amplitude cycles with a 4-11 year period. Alpine time-series were predominantly non-cyclic, while the limited number of series from Russia showed high amplitude weak cycles with an 8-11 year period. The results reveal that mountain hare populations show a wide range of population dynamics with distinct regional differences in periodicity, amplitude and density dependent structure of cycles. These findings suggest that different factors may limit or regulate mountain hare populations in different regions of Europe thus supporting the results of recent field studies.
\end{abstract}

Studies of the cyclic fluctuations of northern vertebrates have played a central role in the development and understanding of population dynamics (Royama 1992, Stenseth 1999, Turchin 2003). Time-series analysis has been widely used to examine temporal abundance data and has yielded important insights into the nature and mechanisms of population dynamics, the role of densitydependence, time lags, scale, and synchrony as well as more applied management issues (Siivonen 1948, Moran 1952, Bulmer 1974, Hudson et al. 1998, Stenseth 1999, Bjørnstad et al. 1999, Thirgood et al. 2000).

One of the best known examples of a cyclic northern vertebrate is the snowshoe hare Lepus americanus in the boreal forests of North America (Keith 1990, Krebs et al. 2001). The population dynamics of the snowshoe hare have been investigated through time-series analysis (Bulmer 1974, Finerty 1980, Royama 1992, Turchin 2003) field study and experiment (Keith et al. 1984, Krebs et al. 1995, Murray et al. 1998). The regular tenyear periodicity of the snowshoe hare cycle shows synchrony throughout the animal's distribution, and may show strong local synchrony (Murray 2000). At the southern extent of their range the available data suggest snowshoe hares show more stable dynamics or low amplitude irregular fluctuations (Keith 1990, Murray 2000). The snowshoe hare is absent from Eurasia where it is replaced in the northern boreal forest by the mountain hare Lepus timidus. 
Mountain hares show periodic fluctuations in abundance throughout their Eurasian distribution and are often described as cyclic (Keith 1983, Angerbjorn 1995). The tendency of mountain hare populations to fluctuate and the period, amplitude and synchrony of cycles are thought to vary geographically (Keith 1983, Lindén 1988, Ranta et al. 1997) but as yet are incompletely described. Here we take advantage of four extensive, long-term data sets of mountain hare abundance indexed from hunting records or questionnaires from Scotland, Sweden, Finland and Switzerland, in addition to less extensive data from Norway, Italy and Russia, to look for evidence of cyclic dynamics. While some analyses of these data have been published (Tapper 1987, Lindén 1988, Ranta et al. 1997), comparisons between studies are hindered by differences in analysis and interpretation. In this paper we have compiled the available long-term data on mountain hare population dynamics in Eurasia. We use timeseries analysis to provide the first comprehensive description of mountain hare population dynamics throughout their distribution.

\section{Methods}

\section{Data sources}

There is currently no national monitoring scheme for wild mammals in Scotland and here we rely on hunting records that are collected by private estates and collated into the National Game Bag Census (NGC) by The Game Conservancy Trust. The NGC database currently holds mountain hare time-series for 212 estates dating from 1850 to 2002 but most series are too short or incomplete to be used. Our analysis is based on 56 series from 51 estates in Scotland and range from 20 to 109 years (Table 1 ).

Although the Statistics Service of Norway have compiled hunting statistics on small game since 1971, data collection, processing and presentation have changed a number of times (Statistics Norway 2002) and we consider the data unsuitable for analysis. Our assessment of Norwegian populations is limited to a reanalysis of three published time-series which range in length from 13-22 years (Table 1) (Moksnes 1972, Hjeljord 1980, Myrberget and Lund-Tangen 1990).

National game bag statistics for Sweden are collected by Swedish Association for Hunting and Wildlife Management and the current database contains records from 25 hunting administrative areas from 1960 to 2002. Mountain hare populations in large areas of Sweden and Norway were affected by a decline in red fox Vulpes vulpes during the 1980s due to an epizootic of sarcoptic mange (Danell and Hörnfeldt 1987, Lindström et al. 1994). We therefore split the series into two periods: $1960-1980$ to represent pre-mange and 1981-2002 to represent post-mange. Although there is a large research literature on mountain hares in Sweden, only three published studies (Hörnfeldt et al. 1986, Danell and Hörnfeldt 1987, Small et al. 1993) including five usable time-series were available (Table 1).

Data on the abundance of small game were collected by the Finnish Game and Fisheries Research Institute by questionnaires sent to a network of observers between 1948-1970. The observers provided an estimate of the relative abundance of mountain hares using a scale of $0-3$ (Andersson and Helminen 1964). Questionnaire responses were averaged by province to provide a density index for each area (Andersson and Helminen 1964, Helminen 1966, 1969, 1971). Although care is needed interpreting such indices the questionnaire data has been considered suitable for time-series analysis (Lindén 1988, Ranta et al. 1997). We also use three published time-series from Siivonen (1948) and Pulliainen (1982) (Table 1).

Mountain hares in central Europe are limited to the Alps of Switzerland, Italy and France. Switzerland records hunting statistics for each of the country's 26 Cantons, which are available in the public domain (Table 1). Mountain hares are not hunted throughout Switzerland, the hunting season is very short and in some years no hares are shot, therefore only 10 Cantons yielded suitable time-series for analysis. Four time-series of mountain hare hunting bags were found in the literature from Italy but only two were suitable for analysis (Scherini and Tosi 1990) (Table 1).

Mountain hares occur in a continuous band throughout the tunda and taiga belts of Russia. Despite this distribution only four time-series were found in the literature (Naumov 1972, Bulmer 1974, Jedrzejewski et al. 1996) (Table 1).

\section{Analysis}

There is little guidance on how long a time-series should be for a meaningful analysis. Turchin (2003) suggests that time-series should be at least 20 years long and be no shorter than three times the suspected period. The reported periodicity of mountain hare cycles varies considerably between regions. To avoid introducing any circularity into our results by using series of different minimum length for each region and to aid comparisons between regions we use a minimum timeseries length of 20 years for the previously unpublished long-term data sets from Scotland, Sweden, Finland and Switzerland. Some of the published time-series are less than 20 years long and in order to maximise our coverage of the literature we include time-series of 12 years or longer. Comparisons between countries 
Table 1. Summary of data and data sources used in this study.

\begin{tabular}{|c|c|c|c|c|c|}
\hline Country & County/state/province & Period & Sampling units & Source & Data provider \\
\hline Scotland & $\begin{array}{l}\text { Regions; Borders, Central, Grampian, } \\
\text { Highland, Lothian, Strathclyde, Tayside, Fife }\end{array}$ & $1850-2002$ & Individuals killed & National Game Census & $\begin{array}{l}\text { Game Conservancy Trust - } \\
\text { electronic data }\end{array}$ \\
\hline Norway & More Og Romsdal (Rindal) & $1945-1966$ & Individuals & Moksnes (1972) & GPDD $(6096)^{\mathrm{b}}$ \\
\hline Norway & Nordland (Ranna) & $1963-1976$ & Individuals & Hjeljord (1980) & Original paper - read from graph \\
\hline Norway & Nord-Trondelag (Meraker) & $1961-1983$ & Individuals shot & Myrberget and Lund-Tangen (1990) & Original paper - read from graph \\
\hline Sweden & 25 hunting administration units & $1960-2002$ & Individuals shot & National Game Bag Statistics & $\begin{array}{l}\text { Swedish Hunters Association-- } \\
\text { electronic data }\end{array}$ \\
\hline Sweden & Gävleborg & $1960-1988$ & $\begin{array}{l}\text { Individuals } \\
\text { Density index }\end{array}$ & Small et al. (1993) & GPDD (6118) \\
\hline Sweden & Västerbotten (Umeå) & $1963-1980$ & $\begin{array}{l}\text { Individuals shot } \\
10000 \mathrm{ha}^{-1}\end{array}$ & Hörnfeldt et al. (1986) & GPDD (10598) \\
\hline Sweden & Norrbotten and Västerbotten & $1970-1984$ & $\begin{array}{l}\text { Individuals killed } \\
1000 \mathrm{ha}^{-1}\end{array}$ & Danell and Hörnfeldt (1987) & GPDD (11015) \\
\hline Sweden & Norrbotten and Västerbotten & $1970-1984$ & $\begin{array}{l}\text { Individuals killed } \\
1000 \mathrm{ha}^{-1}\end{array}$ & Danell and Hörnfeldt (1987) & GPDD (11016) \\
\hline Sweden & Norrbotten and Västerbotten & $1970-1984$ & $\begin{array}{l}\text { Individuals killed } \\
1000 \mathrm{ha}^{-1}\end{array}$ & Danell and Hörnfeldt (1987) & GPDD (11017) \\
\hline Finland & Turku, Lansi-Suomen Laani & $1836-1876$ & Individuals caught & Siivonen (1948) & GPDD (6113) \\
\hline Finland & Topia, Etala-Suomen Laani & $1894-1934$ & Individuals caught & Siivonen (1948) & GPDD (6114) \\
\hline Finland & Finnish Lapland & & $\begin{array}{l}\text { Tracks in snow } \\
\text { per } 100 \mathrm{~m}\end{array}$ & Pulliainen (1982) & Original paper - read from graph \\
\hline Finland & $\begin{array}{l}11 \text { administrative units; Turun ja Porin, } \\
\text { Uudenmaan, Kymen, Hameen, Mikkelin, } \\
\text { Pohjois-Karjalana }{ }^{\mathrm{a}} \text {, Kuopoion, } \\
\text { Keski-Suomen }^{\mathrm{a}}, \text { Vaasan, Oulun, Lapin }\end{array}$ & $1948-1970$ & $\begin{array}{l}\text { Relative } \\
\text { abundance }\end{array}$ & $\begin{array}{l}\text { Andersson and Helminen (1964) } \\
\text { Helminen }(1966,1969,1971)\end{array}$ & Original paper - tabulated data \\
\hline Russia & Komi, Komi Republic (NW Russia) & $1922-1942$ & $\begin{array}{l}\text { Percent of'normal' } \\
\text { harvest }\end{array}$ & Naumov (1972) & GPDD $(3737)^{b}$ \\
\hline Russia & Gatchina, Komi Republic (NW Russia) & $1884-1908$ & Individuals & Naumov (1972) & GPDD (3741) \\
\hline Russia & Yakutia (NE Russia) & $1924-1958$ & $\begin{array}{l}\text { Individuals caught } \\
(\% \text { of mean) }\end{array}$ & Bulmer (1974) & GPDD (6134) \\
\hline Russia & Novgorodskaya (NW Russia) & $1961-1983$ & $\begin{array}{l}\text { Individuals per } \\
100 \mathrm{~km}^{2}\end{array}$ & Jedrzejewski et al. (1996) & $\operatorname{GPDD}(31360)^{b}$ \\
\hline Switzerland & 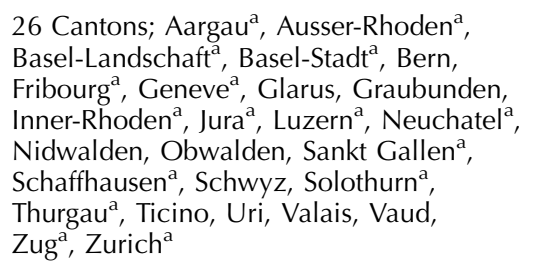 & $1953-2002$ & Individuals killed & National Game Bag Statistics & $\begin{array}{l}\text { Bundesamt für Umwelt, Wald und } \\
\text { Landscahft - electronic data }\end{array}$ \\
\hline Italy & $\begin{array}{l}\text { Four regions; Aosta, Sondrio }{ }^{\mathrm{a}}, \\
\text { Trento }^{\mathrm{a}} \text {, Bolzano }\end{array}$ & & Individuals killed & Scherini and Tosi (1990) & \\
\hline
\end{tabular}


however are confined to the longer ( $>20$ year) timeseries.

Time-series that contained more than $10 \%$ missing data or more than three consecutive missing data points were truncated, or if the series was long enough, split to form shorter series, or else discarded. Three or fewer consecutive missing data points were interpolated from log-transformed data using the Pastecs package in $\mathrm{R}$ (Ibanez 2002, Anonymous 2004). Time-series were transformed to natural logarithms to stabilise variance and convert multiplicative to additive processes. Series that contained zero values were either split if long enough or discarded. Examination of time-series plots showed that many series were affected by trend and we therefore detrended all of the series prior to analysis using a LOESS regression (span 0.75) (Trexler and Joseph 1993, Kendall et al. 1998).

The amplitude of fluctuations was measured using the estimated coefficient of variation $(\mathrm{CV})$ of the interpolated non-transformed series; the (sample standard deviation)/(number of animals killed or index value) (Lande et al. 2003). We used the detrended series to calculate the autocorrelation function (ACF) and identified the dominant period of each series by finding the first maximum in the ACF correlelograms. Series were classified using the Bartlett criteria and considered cyclic if the first maximum in the ACF correlelogram, $\operatorname{ACF}(T)$, exceeded $2 / \sqrt{ } n$, where $n$ equals the length of the series; or as weakly-cyclic if only the ACF at half the dominant period, $\operatorname{ACF}(T / 2)$, was less than $-2 \sqrt{ } \mathrm{n}$; otherwise the series was classed as non-cyclic (Berryman 2002, Turchin 2003).

Identifying the density-dependent structure of a series can serve as a guide for identifying plausible candidates for the mechanisms producing the observed dynamics. First-order density-dependence may result from direct resource competition, second-order densitydependence is considered a sign of trophic interactions such as predator-prey or parasite-host relationships, whilst third-order dynamics can be suggestive of threeway trophic interactions such as vegetation-herbivorepredator (Royama 1992, Berryman 2002, Turchin 2003). We investigated the density-dependent structure of each time-series using the partial rate correlation function which has been shown to be more effective at detecting first-order processes than the widely used partial autocorrelation function (Berryman and Turchin 2001). We plotted the partial rate correlation coefficients against time and assessed the significance of the first 7 time-lags. The process order was considered significant if the partial rate correlation coefficient at a given time lag was less than $-2 / \sqrt{ } n$. The rate of detection of density-dependence has been showed to increase with increasing series length up to a length of 20 years and then stabilises (Woiwood and
Hanski 1992). Therefore, to investigate the occurrence of density-dependence and to compare the densitydependent structures between countries we used only the longer data sets from Scotland, Sweden, Finland and Switzerland.

All analyses were performed using the $\mathrm{R}$ statistics package (v 1.9.1, Anonymous 2004).

\section{Results}

\section{Scotland}

Overall 52\% of the Scottish series examined were classified as cyclic $(13 \%)$ or weakly cyclic $(39 \%)$ with a mean periodicity of 9.2 years and range from 4-15 years (Table 2). The estimated CV suggests that time-series are characterised by high amplitude fluctuations (Table 2). Most of the data come from the northern and central highlands of Scotland and thus it is difficult to discern regional patterns although there was a trend for shorter period cycles in southern Scotland (Fig. 1a).

\section{Norway}

The time-series from south-west Norway collected by Moksnes (1972) revealed cyclic dynamics with a 3-year periodicity. Hjeljord's (1980) and Myrberget and Lund-Tangen's (1990) time-series from Nordland in central Norway were classified as non-cyclic and weakly cyclic with a 7-year periodicity respectively (Table 2 ). All three time-series are characterised by low-amplitude fluctuations compared to those found in Scotland (Table 2).

\section{Sweden}

The 25 Swedish time-series from pre-mange and postmange periods were predominantly non-cyclic with only $32 \%$ showing weak cyclic dynamics (Table 2 ). The 8 series in the 1960-1980 pre-mange period that were classified as weakly cyclic showed a mean periodicity of 3.9 years (range 3-5) compared to a longer mean periodicity 6.4 years (range $5-8$ ) exhibited by the 8 weakly cyclic series in the post-mange period (Table 2). The characteristic consistent lowamplitude fluctuations of the 1960-80 pre-mange period were replaced by more variable and higher amplitude fluctuations in the 1980-2002 post-mange period (Table 2). Although the proportion of noncyclic time-series was the same in both time periods there was a change in the distribution of weakly cyclic populations. Time-series from only three counties were 
Table 2. Amplitude and the proportion of cyclic, weakly-cyclic and non-cyclic time series in each region and data set.

\begin{tabular}{|c|c|c|c|c|c|c|c|}
\hline Country/data source & No of series & Length (years) & Mean amplitude (range) & Non-cyclic & Weakly cyclic & Cyclic & Mean periodicity (range) \\
\hline \multicolumn{8}{|l|}{ Scotland } \\
\hline \multicolumn{8}{|l|}{ NGC Data } \\
\hline Highland & 17 & $20-109$ & $0.89(0.58-1.38)$ & $7(41 \%)$ & $8(47 \%)$ & $2(12 \%)$ & $10.1(5-15)$ \\
\hline Grampian & 9 & $25-79$ & $1.04(0.50-1.80)$ & $7(78 \%)$ & $1(11 \%)$ & $1(11 \%)$ & $10(9-11)$ \\
\hline Tayside & 18 & $23-72$ & $0.98(0.56-1.74)$ & $8(44 \%)$ & $8(44 \%)$ & $2(12 \%)$ & $9.7(5-14)$ \\
\hline Central & 1 & 60 & $0.96(-)$ & $1(100 \%)$ & & & \\
\hline Lothian & 2 & $30-44$ & $0.75(0.74-0.76)$ & & $2(100 \%)$ & & $5.0(-)$ \\
\hline Strathclyde & 4 & $35-88$ & $0.58(0.51-0.72)$ & $2(50 \%)$ & & $2(50 \%)$ & $8.5(8-9)$ \\
\hline Fife & 1 & 24 & $0.50(-)$ & $1(100 \%)$ & & & \\
\hline Borders & 4 & $28-37$ & $0.80(0.39-1.24)$ & $1(25 \%)$ & $3(75 \%)$ & & $7.0(4-10)$ \\
\hline Overall & 56 & $20-109$ & $0.81(0.39-1.80)$ & $27(48 \%)$ & $22(39 \%)$ & $7(13 \%)$ & $9.2(4-15)$ \\
\hline \multicolumn{8}{|l|}{ Norway } \\
\hline Moksnes (1972) & 1 & 21 & $0.68(-)$ & & & $1(100 \%)$ & $3(-)$ \\
\hline Hjeljord (1980) & 1 & 13 & $0.59(-)$ & $1(100 \%)$ & & & \\
\hline Myrberget et al. (1990) & 1 & 22 & $0.39(-)$ & & $1(100 \%)$ & & $7(-)$ \\
\hline \multicolumn{8}{|l|}{ Sweden } \\
\hline Game bags 1960-1980 & 25 & 20 & $0.34(0.19-0.59)$ & $17(68 \%)$ & $8(32 \%)$ & & $3.9(3-5)$ \\
\hline Game bags $1981-2002$ & 25 & 22 & $0.70(0.5-1.12)$ & $17(68 \%)$ & $8(32 \%)$ & & $6.4(5-8)$ \\
\hline Hörnfeldt et al. (1986) & 1 & 17 & $0.68(-)$ & & & $1(100 \%)$ & $4(-)$ \\
\hline Danell et al. (1987) & 3 & 14 & $0.56(0.44-0.66)$ & & $1(33 \%)$ & $2(67 \%)$ & $4(-)$ \\
\hline Small et al. (1993) & 1 & 29 & $0.76(-)$ & $1(100 \%)$ & & & \\
\hline \multicolumn{8}{|l|}{ Finland } \\
\hline Winter Game Enquiry & 9 & 22 & $0.16(0.09-0.23)$ & $3(33 \%)$ & $6(67 \%)$ & & $5.3(4-7)$ \\
\hline Pulliainen (1982) & 1 & 13 & $0.51(-)$ & $1(100 \%)$ & & & \\
\hline Siivonen (1948) & 2 & 40 & $0.57(0.52-0.63)$ & $1(50 \%)$ & $1(50 \%)$ & & $11(-)$ \\
\hline \multicolumn{8}{|l|}{ Switzerland } \\
\hline Game bags & 10 & $27-49$ & $\begin{array}{c}0.53(0.26-1.88) \\
{[0.38(0.26-0.55)]^{1}}\end{array}$ & $7(70 \%)$ & $3(30 \%)$ & & $4.6(4-6)$ \\
\hline \multicolumn{8}{|l|}{ Italy } \\
\hline Scherini and Tosi (1990) & 2 & $16-18$ & $0.26(0.21-0.31)$ & $1(50 \%)$ & $1(50 \%)$ & & $6(-)$ \\
\hline \multicolumn{8}{|l|}{ Russia } \\
\hline Naumov (1972) & 2 & 23 & $0.56(0.53-0.58)$ & $1(50 \%)$ & $1(50 \%)$ & & $8(-)$ \\
\hline Bulmer (1974) & 1 & 35 & $1.05(-)$ & & & $1(100 \%)$ & $11(-)$ \\
\hline Jedrzejewski et al. (1996) & 1 & 23 & $0.36(-)$ & $1(100 \%)$ & & & \\
\hline
\end{tabular}

${ }^{1}$ excluding one extreme data point. 


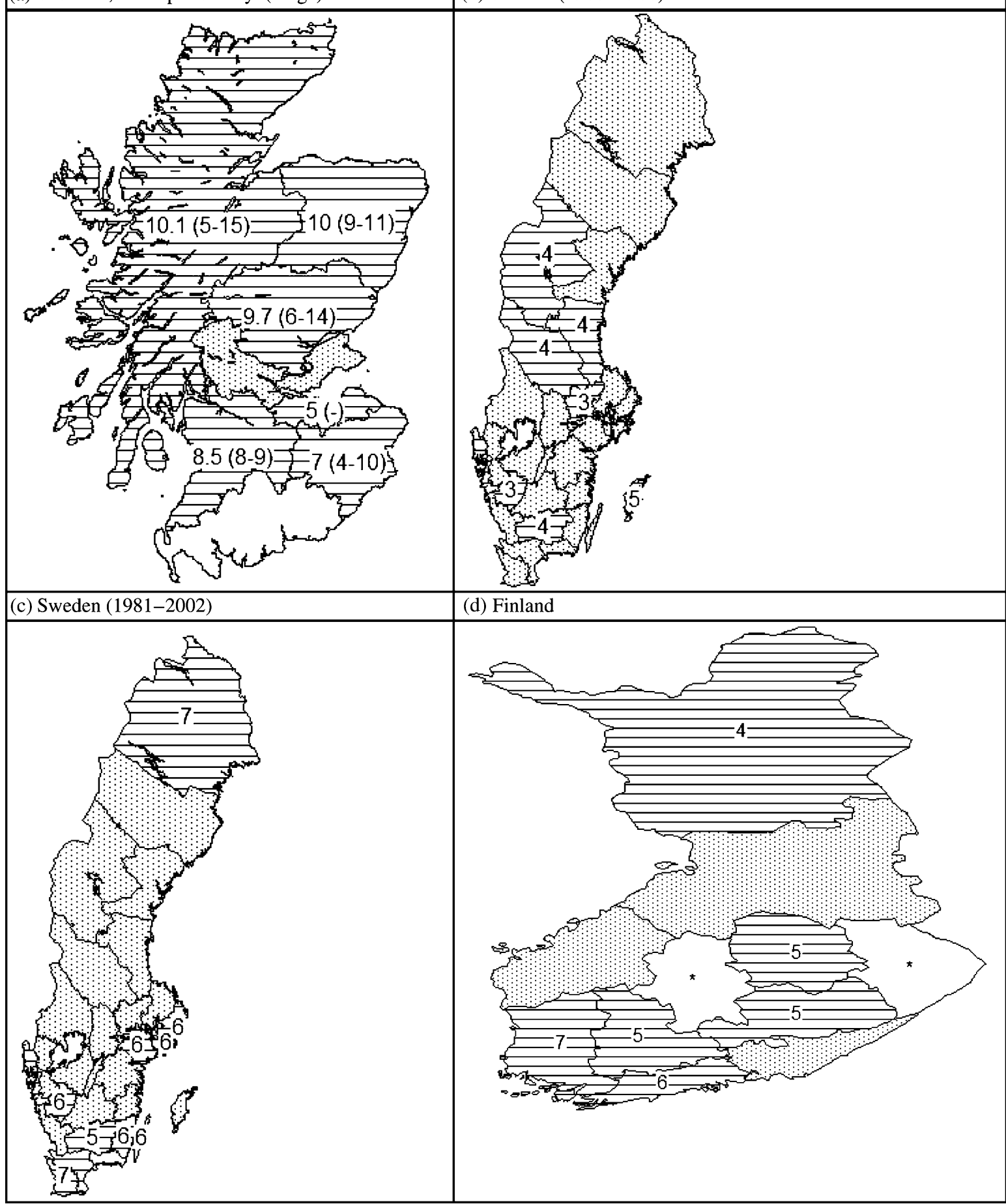

Fig. 1. The distribution and periodicity (range) of cyclic, weakly cyclic and non-cyclic time-series of mountain hares in: (a) Scotland, (b) Sweden (1960-1981), (c) Sweden (1981-2002) and (d) Finland. Horizontal shading-cyclic or weakly cyclic series, spotted shading-areas non-cyclic, blank $/{ }^{*}$-indicates no data were available.

classified as weakly cyclic both before and after mange (Fig 1b, 1c). The central counties that exhibited 3-5 year weak cycles in the pre-mange period (Fig. 1b) were non-cyclic after the mange epizootic, while there was an increase in weak cyclic series in southern and eastern Sweden (Fig. 1c). 
The time-series from Gävleborg in central Sweden from both pre-mange and post-mange periods compiled by Small et al. (1993) was non-cyclic. Four published time-series were available from northern Sweden. The series from Västerbotten encompassing both the pre- and post-mange periods (Hörnfeldt et al. 1986) was cyclic with a 4-year periodicity. Two of the three time-series extracted from Danell and Hörnfeldt (1987) from Västerbotten and Norbotten were cyclic and one was weakly cyclic and all showed a periodicity of 4 years (Table 2).

\section{Finland}

Six of the time-series from the Finnish Winter Game Enquiry were classified as showing weak cyclic dynamics with a mean periodicity of 5.3 years (range 4-7 years) and the remaining three time-series were classified as non-cyclic (Table 2). With exception of Lapland in northern Finland, all of the weak cyclic series were in south-west and central Finland (Fig. 1d). All the series consistently showed low amplitude fluctuations.

Two time-series from south-west Finland based on trapping data were extracted from Siivonen (1948). The series from Lansi-Suomen Laani was cyclic with an 11 year periodicity while the series from EtalaSuomen Laani was non-cyclic. The short time-series of snow track data from Finnish Lapland extracted from Pulliainen (1982) was non-cyclic (Table 2).

\section{European Alps}

Seven of the ten series analysed from Swiss Alpine populations of mountain hares were classified as noncyclic and three (Nidwalden, Schwyz and Ticini) were weakly cyclic with a mean periodicity of 4.6 years (range 4-6 years). One of the two time-series from the Italian Alps was non-cyclic and one (Bolzano) was weakly cyclic with a periodicity of 6 years (Table 2). Compared to Scotland the time-series from both Switzerland and Italy show low amplitude fluctuations similar to those found in Sweden and Finland (Table 2).

\section{Russia}

One of the two series from the Kommi Republic in northwest Russia extracted from Naumov (1972) exhibited a weak cycle with a periodicity of 8 years whilst the second series was non-cyclic. The series from Novgorodskaya in northwest Russia published by Jedrzejewski et al. (1996) was non-cyclic. The timeseries from Yakutskaya in the Russian Far East compiled by Bulmer (1974) was cyclic with an 11-year periodicity (Table 2). This time-series showed high amplitude fluctuations comparable to those identified in Scottish time-series, while the nonand weakly- cyclic series showed low amplitude fluctuations of magnitude similar to those in Fennoscandia (Table 2).

\section{Process order and density-dependence}

The seven cyclic series from the long-term extensive data set, all from Scotland, were dominated by first and higher order processes suggesting both direct and delayed density-dependence (Table 3). Although there are geographic differences in the distribution of processes within the weakly cyclic series in Scotland, Sweden, Finland and Switzerland, these series were also predominantly driven by first order processes acting together with higher order processes (Table 3 ). In contrast, the non-cyclic series in these four countries appear either to be dominated by first order processes or no significant process order could be identified (Table 3).

\section{Discussion}

This is the first study to categorise the population dynamics of mountain hares throughout their range. By identifying time-series from a variety of sources and using the same methods of data analysis, we provide the first comprehensive description of mountain hare population dynamics and the occurrence and distribution of population cycles in Eurasia. We analysed 142 time-series in this study, of which $8 \%$ were cyclic, $37 \%$ were weakly cyclic and the remaining 55\% were noncyclic. The periodicity of cyclic and weakly cyclic dynamics was highly variable across the distribution ranging from three to fifteen years. Similarly, the amplitude of observed cycles also showed considerable variation.

A previously published analysis of mountain hare bag records from Scotland, based on 20 time-series, suggested that hare populations were best described as "phase-forgetting quasi-cyclic" with a mean periodicity of 9.5 years (Tapper 1987). Our analysis of 56 timeseries, incorporating all of the previously analysed data, has resulted in broadly similar results, with just over half of all series classified as cyclic or weakly cyclic, with a mean periodicity of 9.2 years. These summary statistics, however, mask a high degree of variability in both the nature of the population fluctuations, as there are high proportions of both non-cyclic and weakly cyclic time-series, and in cycle periodicity which ranges from $4-15$ years.

Our analysis indicated that just under a third of Swedish mountain hare time-series show weakly cyclic dynamics. Swedish hare populations are characterised by high-frequency and low-amplitude dynamics 
Table 3. The occurrence of process order identified in cyclic, weakly cyclic and non-cyclic time-series for the four long-term data sets from Scotland, Sweden, Finland and Switzerland.

\begin{tabular}{|c|c|c|c|c|c|c|c|c|}
\hline Cyclic & $\mathrm{n}$ & None & 1st only & $1 \mathrm{st}+$ & 1 st and 2 nd & 2nd only & 2 nd + & Other \\
\hline $\begin{array}{l}\text { Scotland } \\
\text { Sweden (1960-1980) } \\
\text { Sweden (1981-2002) } \\
\text { Finland } \\
\text { Switzerland }\end{array}$ & $\begin{array}{l}7 \\
0 \\
0 \\
0 \\
0\end{array}$ & & $2(29 \%)$ & $4(57 \%)$ & $1(14 \%)$ & & & \\
\hline $\begin{array}{l}\text { Weakly-cyclic } \\
\text { Scotland } \\
\text { Sweden (1960-1980) } \\
\text { Sweden (1981-2002) } \\
\text { Finland } \\
\text { Switzerland }\end{array}$ & $\begin{array}{r}22 \\
8 \\
8 \\
6 \\
3\end{array}$ & $\begin{array}{l}1(5 \%) \\
1(17 \%)\end{array}$ & $\begin{array}{l}7(32 \%) \\
1(13 \%) \\
1(13 \%)\end{array}$ & $\begin{array}{l}10(45 \%) \\
1(13 \%) \\
2(33 \%) \\
1(33 \%)\end{array}$ & $\begin{array}{l}1(5 \%) \\
3(38 \%) \\
3(38 \%) \\
1(17 \%) \\
2(66 \%)\end{array}$ & $\begin{array}{l}2(9 \%) \\
2(25 \%) \\
1(13 \%) \\
1(17 \%)\end{array}$ & $\begin{array}{ll}1 & (13 \%) \\
1 & (13 \%) \\
1 & (17 \%)\end{array}$ & $\begin{array}{ll}1 & (5 \%) \\
1 & (13 \%) \\
1 & (13 \%)\end{array}$ \\
\hline $\begin{array}{l}\text { Non-cyclic } \\
\text { Scotland } \\
\text { Sweden (1960-1980) } \\
\text { Sweden (1981-2002) } \\
\text { Finland } \\
\text { Switzerland }\end{array}$ & $\begin{array}{r}27 \\
17 \\
17 \\
3 \\
7\end{array}$ & $\begin{array}{l}2(7 \%) \\
4(24 \%) \\
8(47 \%) \\
1(33 \%)\end{array}$ & $\begin{array}{r}20(74 \%) \\
10(59 \%) \\
7(41 \%) \\
2(66 \%) \\
5(71 \%)\end{array}$ & $2(29 \%)$ & $2(7 \%)$ & $1(6 \%)$ & & $\begin{array}{l}2(12 \%) \\
2(12 \%)\end{array}$ \\
\hline
\end{tabular}

1 st: first order process only.

1 st + : first, and one or more higher order processes.

1 st and 2 nd: first and second order processes only.

2nd: second order processes only.

2nd + : second, and one or more higher order processes.

Other; one or more processes of 3 rd order or higher.

compared to the low-frequency and high-amplitude dynamics identified in the Scottish mountain hare bag data. The estimated periodicity obtained from our reanalysis of published time-series agrees closely with our analysis of the longer-term hunting records from 1960-1980 which show roughly a 4-year periodicity, though periodicity increases to 6 years in the later 1980-2002 series. Hörnfeldt et al.'s (1986) suggestion that northern Swedish mountain hare populations exhibit 4-year cycles, based on visual assessment of the time-series, is confirmed by our reanalysis of those data. However, the occurrence of cyclic dynamics in Hörnfeldt et al.'s (1986) data runs contrary to the results of our analysis of the long-term hunting statistics from the same area which revealed no cyclic time-series. One possible explanation for this disparity might be that Hörnfeldt et al. (1986) used an index of the number of hares shot per 10000 ha from a $10000 \mathrm{~km}^{2}$ area around Umeå, whereas our analysis is based on number of hares shot over the whole of Västerbotten.

Our study suggests that the dynamics of Swedish mountain hare populations changed following the outbreak of sarcoptic mange in red foxes in the 1970s. Whilst the proportion of mountain hare timeseries showing weakly cyclic dynamics remained at around one third the periodicity of the cycles increased from 4 to 6 years. The alternate prey hypothesis (APH) predicts that the red fox, which preferentially prey on cyclic populations of voles Microtus agrestis during the peak of the 4-year vole cycle, switch to preying on small game including mountain hares as vole numbers decrease, thus transferring the 4-year vole cycle to mountain hares (Hörnfeldt 1978, Marcström et al. 1989, Small et al. 1993). The outbreak of sarcoptic mange among foxes in Norway and Sweden and subsequent decline in fox numbers from the late1970s to the mid-1980s provided a natural test of the $\mathrm{APH}$. Previous studies that investigated the effect of reduced fox numbers on hare populations found that hare numbers increased in abundance and tended to become less cyclic as fox numbers declined (Danell and Hörnfeldt 1987, Lindström et al. 1994). The effect of mange on fox numbers was most severe in northern and central Sweden which corresponds to counties which in our analysis were weakly cyclic in the pre-mange period but were non-cyclic in the post-mange period.

Previous time-series studies of changes in mountain hare abundance in Finland based on the Finnish Winter Game Enquiry have shown the widespread occurrence of cycles ranging from 4-11 years with shorter cycles in the north giving way to longer cycles in the south (Lindén 1988, Ranta et al. 1997). These spatial patterns in mountain hare dynamics are matched by other small game species including forest grouse and it has been hypothesised that the longer cycle period and lower amplitude is a result of habitat fragmentation and increased predator densities in southern Finland (Kurki et al. 1998). The results from our study differ in that we found that cyclic dynamics in mountain hare populations were found primarily in central and southern Finland 
whereas time-series from northern Finland were noncyclic. Direct comparison between the previous two studies and our study is difficult due to differences in methodology with Lindén (1988) using autocorrelation analysis of arithmetic, non-detrended indices and Ranta et al. (1997) using spectral analysis of standardised and detrended indices.

To our knowledge there are few published studies on mountain hare population dynamics in the European Alps. It is therefore difficult to put our findings into context, especially given the limited geographic coverage and small number of series available. Investigation of mountain hare population dynamics in Russia has also been hampered by the shortage of suitable long-term data. Formozov's (1935) appraisal of the occurrence and distribution of cyclic dynamics in Russian mountain hare populations, which was evidently based on data that were never published, suggested that cycles occurred with a 10-year period in the northern tundra and a 6 -year period in the southern taiga belt. The amplitude of cycles was thought to be very high with density changing up to 50-fold. Our assessment of mountain hare population dynamics in Russia is equivocal with only two of the four series, one from north-west and one from north-east Russia showing weak cyclic dynamics (8-year and 11-year periodicity) with the remaining two series, both from north-west Russia, being non-cyclic. Our understanding of mountain hare ecology in this region is largely confined to the few studies that have been translated into English. The Russian tundra and taiga biomes represent a substantial proportion of the geographic range of mountain hares. Furthermore, many of the time-series from Europe used in this study are from landscapes strongly influenced by human activities, and data from less intensively managed areas such as the Russian tundra and taiga may provide considerable insight into the drivers of cyclic dynamics in mountain hares. For both of these reasons we suggest that accessing the Russian literature should be a priority.

The predominance of first and higher order processes, representing delayed density dependence, in the cyclic and weakly cyclic series is consistent with the view that unstable dynamics are more likely when there are time lags in the system (May 1981). While the occurrence of second and third order processes might be interpreted as evidence for a two or three level trophic interaction (Royama 1992, Stenseth 1999, Turchin 2003), the lack of a clear pattern in this study does not allow any inference about the nature of trophic interactions in these systems. The high proportion of first-order processes in the series identified as non-cyclic might suggest that these populations are regulated around a stable equilibrium by direct density-dependent mechanisms such as food limitation, however they could also potentially be a statistical artefact of the detrending process.
Reliance on hunting statistics as used extensively in this study assumes that the records reflect hare numbers. To our knowledge this assumption has never been directly tested for mountain hares. Hewson (1976) found a strong association between mountain hare bag records in Scotland and estimates of hare density assessed by capture-mark-recapture. Cattadori et al. (2003) demonstrated that shooting bag records of red grouse Lagopus lagopus scoticus accurately reflected grouse densities as determined by sample counts with pointing dogs. Mountain hares are not, however, as financially important a game species as red grouse or willow grouse and their harvest may potentially be influenced by factors other than their abundance.

In conclusion, time-series analysis of hunting statistics and other abundance indices demonstrate that mountain hare populations often show unstable dynamics characterised by weak cycles. We found little evidence to support the current existence of 4-year cycles in northern Fennoscandia and there appears to have been a change in the distribution and occurrence of cycles in Sweden following the sarcoptic mange epizootic of the late 1970s. In contrast to the 10-year cycle of snowshoe hares in the boreal forest of North America, mountain hares in northern Eurasia demonstrate considerable variation in the occurrence, periodicity and amplitude of cyclic dynamics. One possible explanation for this variability is that different factors may drive unstable dynamics in mountain hares in different geographical areas. This hypothesis is supported by the available literature (reviewed by Newey et al. 2007) which suggests that mountain hare populations in Fennoscandia are limited by generalist predators such as red fox (Marcström et al. 1989, Lindström et al. 1994). In Scotland on the other hand, predators are killed by gamekeepers and predation is thought to have little impact on mountain hare dynamics (Hewson 1976, 1984). Recent research in Scotland suggests that mountain hare populations on moorland managed for red grouse may be limited by intestinal parasites (Newey and Thirgood 2004, Newey et al. 2005).

Acknowledgements - We thank generations of hunters for diligently recording mountain hare bags. This research was funded by the Game Conservancy Trust, Game Conservancy Scottish Research Trust, Swedish Institute, Swedish Sportsman's Association and the Scottish Executive Environment and Rural Affairs Department. We thank Glenn Iason and Esa Ranta for helpful comments on the manuscript.

\section{References}

Andersson, P. and Helminen, M. 1964. Relative abundance of Lepus timidus and L. europaeus in Finland in 1948-63 
and their diseases in 1955-63. - Suomon Riista 17: 53-64.

Anonymous 2004. R: a language and environment for statistical computing. 2004. - R Foundation for Statistical Computing, Vienna, Austria.

Berryman, A. A. 2002. Population cycles: causes and analysis. - In: Berryman, A. A. (ed.), Population cycles. Oxford Univ. Press, pp. 3-28.

Berryman, A. and Turchin, P. 2001. Identifying the densitydependent structure underlying ecological time series. - Oikos 92: 265-270.

Bjørnstad, O. N. et al. 1999. Synchrony and scaling in dynamics of voles and mice in northern Japan. - Ecology 80: 622-637.

Bulmer, M. G. 1974. A statistical analysis of the 10-year cycle in Canada. - J. Anim. Ecol. 43: 701-718.

Cattadori, I. M. et al. 2003. Are indirect measures of abundance a useful index of population density? The case of red grouse harvesting. - Oikos 100: 439-446.

Danell, K. and Hörnfeldt, B. 1987. Numerical responses by populations of red fox and mountain hare during an outbreak of sarcoptic mange. - Oecologia 73: 533-536.

Finerty, J. P. 1980. The population ecology of cycles in small mammals. - Yale Univ. Press.

Formozov, A. N. 1935. Fluctuations in the numbers of economically exploited animals. - All-Union Coop. Unified Publishing House.

Helminen, M. 1966. Relative abundance of some game and fur species in Finland at the end of the 1964/65 and 1965/66 hunting seasons. - Suomon Riista 19: 145-155.

Helminen, M. 1969. Relative abundance of some game and fur species in Finland at the end of the 1966/67 and 1967/68 hunting seasons. - Suomon Riista 21: $116-127$.

Helminen, M. 1971. Relative abundance of some game and fur species in Finland at the end of the 1968/69 and 1969/70 hunting seasons. - Suomon Riista 23: $136-146$.

Hewson, R. 1976. A population study of mountain hares (Lepus timidus) in north-east Scotland from 1956-1969. - J. Appl. Ecol. 45: 395-414.

Hewson, R. 1984. Mountain hare, Lepus timidus, bags and moor management. - J. Zool. 204: 563-565.

Hjeljord, O. 1980. Viltbiologie. - Landbruksforlaget.

Hörnfeldt, B. 1978. Synchronous population fluctuations in voles, small game, owls, and tularaemia in northern Sweden. - Oecologia 32: 141-152.

Hörnfeldt, B. et al. 1986. Cycles in voles and small game in relation to variations in plant production indices in northern Sweden. - Oecologia 68: 496-502.

Hudson, P. J. et al. 1998. Prevention of population cycles by parasite removal. - Science 282: 2256-2258.

Ibanez, F. et al. 2002. pastecs: package for analysis of spacetime ecological series. - SciViews

Jedrzejewski, W. et al. 1996. Population dynamics (18691994), demography, and home ranges of the lynx in Bialowieza Primeval Forest (Poland \& Belarus). - Ecography 19: 122-138.

Keith, L. B. 1983. Role of food in hare population cycles. - Oikos 40: 385-395.
Keith, L. B. 1990. Dynamics of snowshoe hare populations. - In: Genoways, H. H. (ed.), Curr. Mammal. Plenum, pp. 119-195.

Keith, L. B. et al. 1984. Demography and ecology of a declining snowshoe hare population. - Wildlife Monogr, pp. $1-43$.

Kendall, B. E. et al. 1998. The macroecology of population dynamics: taxonomic and biogeographical patterns in population cycles. - Ecol. Lett. 1: 160-164.

Krebs, C. J. et al. 1995. Impact of food and predation on the snowshoe hare cycle. - Science 269: 1112-1115.

Krebs, C. J. et al. 2001. Ecosystem dynamics of the boreal forest. - Oxford Univ. Press.

Kurki, S. et al. 1998. Abundances of red fox and pine marten in relation to the composition of boreal forest landscapes. - J. Anim. Ecol. 67: 874-886.

Lande, R. et al. 2003. Stochastic population dynamics in ecology and conservation. - Oxford Univ. Press.

Lindén, H. 1988. Latitudinal gradients in predator-prey interactions, cyclicity and synchronism in voles and small game populations in Finland. - Oikos 52: 341-349.

Lindström, E. R. et al. 1994. Disease reveals the predator: sarcoptic mange, red fox predation, and prey populations. - Ecology 75: 1042-1049.

Marcström, V. et al. 1989. Demographic responses of arctic hares (Lepus timidus) to experimental reductions of red foxes (Vulpes vulpes) and martens (Martes martes). - Can. J. Zool. 67: 658-668.

May, R. M. 1981. Models for two interacting populations. - In: May, R. M. (ed.), Theoretical ecology. Blackwell, pp. $78-104$.

Moksnes, A. 1972. Bestandsvingninger hos småviltarter i Trollheimsområdet. - Naturen 5: 319.

Moran, P. A. P. 1952. The statistical analysis of game-bird records. - J. Anim. Ecol. 21: 154-158.

Murray, D. L. 2000. A geographic analysis of snowshoe hare population demography. - Can. J. Zool. 78: 1207-1217.

Murray, D. L. et al. 1998. Do parasitism and nutritional status interact to affect production in snowshoe hares? - Ecology 79: 1209-1222.

Myrberget, S. and Lund-Tangen, H. I. 1990. Cyclic variations in small game populations in central Norway. - In: Myrberget, S. (ed.), Trans. 19th Int. Union of Game Biologists Congr. Trondhiem. NINA, Norw. Inst. Nat. Res. 1, pp. 93-96.

Naumov, S. P. 1972. The ecology of animals. The Board of Trustees of the Univ. of Illinois. Originally published as Ekologiya zhivotnykh by the Higher School State Publishers, Moscow, 1963.

Newey, S. and Thirgood, S. J. 2004. Parasite-mediated reduction in fecundity of mountain hares. - Proc. R. Soc. Lond. B. 271: S413-S415.

Newey, S. et al. 2005. Prevalence, intensity and aggregation of intestinal parasites in mountain hares and their potential impact on population dynamics. - Int. J. Parasitol. 35: $367-373$.

Newey, S. et al. 2007. Unstable dynamics and population limitation in mountain hares. - Biol. Rev. in press

Pulliainen, E. 1982. Habitat selection and fluctuations in numbers in a population of the arctic hare (Lepus timidus) 
on a subarctic fell in Finnish forest Lapland. - Z. Saugetierkunde 47: 168-174.

Ranta, E. et al. 1997. Solar activity and hare dynamics: a cross-continental comparison. - Am. Nat. 149: 765775.

Royama, T. 1992. Analytical population dynamics. - Chapman \& Hall.

Scherini, G. and Tosi, G. 1990. Correlation between grouse and mountain hare hunting bags. - In: Myrberget, S. (ed.), Trans. 19th Int. Union of Game Biologists Congr., Trondheim. NINA, Norw. Inst. Nat. Res. 1: 97- 100 .

Siivonen, L. 1948. Structure of short cyclic fluctuation in numbers of mammals and birds in the northern parts of the northern hemisphere. - Papers Game Res. 1: $1-166$.

Statistics Norway 2002. Hunting Statistics 2002. - Statistics Norway, Oslo.
Small, R. J. et al. 1993. Synchronous and non-synchronous population fluctuations of some predators and their prey in central Sweden. - Ecography 16: 360-364.

Stenseth, N. C. 1999. Population cycles in voles and lemmings: density dependence and phase dependence in a stochastic world. - Oikos 87: 427-461.

Tapper, S. C. 1987. Cycles in game-bag records of hares and rabbits in Britain. - Symp. Zool. Soc. Lond. 58: 79-98.

Thirgood, S. J. et al. 2000. Habitat loss and raptor predation: disentangling long- and short-term causes of red grouse declines. - Proc. R. Soc. Lond. B. 267: 651-656.

Trexler, J. C. and Joseph, T. 1993. Nontraditional regression analyses. - Ecology 74: 1629-1637.

Turchin, P. 2003. Complex population dynamics: a theoretical/empirical synthesis. - Princeton Univ. Press.

Woiwood, I. P. and Hanski, I. 1992. Patterns of density dependence in moths and aphids. - J. Anim. Ecol. 61: 619-629. 